\title{
C-C chemokine receptor type 5 links COVID-19, rheumatoid arthritis, and Hydroxychloroquine: in silico analysis
}

\author{
Mahmood Y. Hachim ${ }^{1}$ (D), Ibrahim Y. Hachim² ${ }^{2}$ Kashif Bin Naeem ${ }^{3}$, Haifa Hannawi ${ }^{3}$, Issa Al Salmi ${ }^{4}$ and \\ Suad Hannawi $i^{3^{*}}$
}

\begin{abstract}
Patients with rheumatoid arthritis (RA) represent one of the fragile patient groups that might be susceptible to the critical form of the coronavirus disease - 19 (COVID-19). On the other side, RA patients have been found not to have an increased risk of COVID-19 infection. Moreover, some of the Disease-Modifying Anti-Rheumatic Drugs (DMARDS) commonly used to treat rheumatic diseases like Hydroxychloroquine (HCQ) were proposed as a potential therapy for COVID-19 with a lack of full understanding of their molecular mechanisms. This highlights the need for the discovery of common pathways that may link both diseases at the molecular side. In this research, we used the in silico approach to investigate the transcriptomic profile of RA synovium to identify shared molecular pathways with that of severe acute respiratory syndrome-corona virus-2 (SARS-COV-2) infected lung tissue. Our results showed upregulation of chemotactic factors, including CCL4, CCL8, and CCL11, that all shared CCR5 as their receptor, as a common derangement observed in both diseases; RA and COVID-19. Moreover, our results also highlighted a possible mechanism through which $\mathrm{HCQ}$, which can be used as a monotherapy in mild RA or as one of the triple-DMARDs therapy (tDMARDs; methotrexate, sulphasalazine, and HCQ), might interfere with the COVID19 infection. This might be achieved through the ability of HCQ to upregulate specific immune cell populations like activated natural killer (NK) cells, which were found to be significantly reduced in COVID-19 infection. In addition to its ability to block CCR5 rich immune cell recruitment that also was upregulated in the SARS-COV-2 infected lungs. This might explain some of the reports that showed beneficial effects.
\end{abstract}

\section{Introduction}

Since the outbreak of Coronavirus disease-19 (COVID19) disease, the clinical features of this disease showed significant variability between different subpopulations. Severe acute respiratory syndrome coronavirus 2 , shortened to SARS-CoV-2, is the virus that causes COVID-19 disease [1]. Initially, patients with chronic conditions, as well as immunodeficiencies, were considered as highrisk groups patients for the development of the more severe form of the COVID-19 [2, 3]. Patients with rheumatoid arthritis (RA), a prevalent immune-mediated

\footnotetext{
* Correspondence: suadhannawi@gmail.com

${ }^{3}$ Ministry of Health and Prevention (MOHAP), Dubai, UAE

Full list of author information is available at the end of the article
}

disease, are at higher risk of bacterial and viral infections due to its pathogenesis and the use of immunosuppressive agents as an RA treatment. As a result, RA patients represent one of those fragile patients groups that might be susceptible to the critical form of the COVID-19 disease [4-6].

Unexpectedly, recent reports showed that patients with RA have no increased risk of COVID-19 infection. Moreover, some of the Disease-Modifying Anti-Rheumatic (DMARDs) that commonly used to treat rheumatic diseases like Hydroxychloroquine (HCQ) were proposed as potential therapies for COVID-19 [7-10]. HCQ is used as monotherapy in mild RA cases, or it can be used as a combined treatment, particularly with methotrexate and sulphasalazine as Triple Disease Anti-Rheumatic Drugs

(c) The Author(s). 2020 Open Access This article is licensed under a Creative Commons Attribution 4.0 International License, which permits use, sharing, adaptation, distribution and reproduction in any medium or format, as long as you give appropriate credit to the original author(s) and the source, provide a link to the Creative Commons licence, and indicate if changes were made. The images or other third party material in this article are included in the article's Creative Commons licence, unless indicated otherwise in a credit line to the material. If material is not included in the article's Creative Commons licence and your intended use is not permitted by statutory regulation or exceeds the permitted use, you will need to obtain permission directly from the copyright holder. To view a copy of this licence, visit http://creativecommons.org/licenses/by/4.0/. 
(tDMARDs) regimen [11]. Several mechanisms were proposed for HCQ to produce its action, and this includes the anti-inflammatory effect through lysosomal acidification interference and phospholipase A2 inhibition [12, 13]. Also, HCQ was proposed to modulate the inflammatory response through its inhibition of the toll-like receptors signal as well as the $\mathrm{T}$ and $\mathrm{B}$ cell receptors leading to inhibition of their cytokine production, including the interleukin (IL)-1 and IL-6 [13, 14]. This cytokine inhibition was proposed as an essential mechanism that might explain the role of HCQ in reducing the cytokine storm critical in COVID-19 pathogenesis [15]. HCQ was also reported to inhibit viral replication [16].

The controversial results that recently linked to the efficacy of HCQ in COVID-19, in addition to the lack of full understanding of its molecular mechanisms, highlight the need for the discovery of common pathways that may link both diseases; COVID-19 and RA at the molecular side. This step is essential for the identification of possible targets that can block pathogenesis of RA and prevent severe forms of COVID19. Also, it might help in identifying the predictive biomarkers that can help in more efficient patient stratification to predict COVID-19 patient's responses to $\mathrm{HCQ}$.

In this study, we used in silico approach to investigate the transcriptomic profile of RA synovium to identify shared molecular pathways with that of SARS-COV-2 infected lung tissue.

\section{Materials and methods \\ RA synovium specific DEG}

The Gene Expression Omnibus (GEO) public repository was used to retrieve the gene expression profile of synovial tissue from 33 RA, 26 osteoarthritis (OA) patients, and 20 healthy controls from three datasets (GSE55235, GSE55457, GSE55584) as previously reported [17]. Raw cell files were reanalyzed using AltAnalyze tool (20) and in house pipeline for normalization and filtration as previously described [18] to identify novel synovium related biomarkers.

\section{tDMARDs response in RA synovium}

We used the publicly available synovial tissue transcriptomic data to compare the infiltration of the immune cells at baseline and after six months of tDMARDs to identify subgroups that might not respond well to tDMARDs. RNAseq dataset (GSE97165) of synovial biopsies taken from 19 early RA (defined as within 12 months of the onset of symptoms) patients at baseline and after six months of tDMARDs treatment were retrieved and reanalyzed.

\section{SARS-COV-2 and RA}

RNAseq dataset (GSE147507) were retrieved using the GEO and used to identify Differentially Expressed Genes (DEGs) between infected and uninfected lung samples using BioJupies tools [19].

\section{Pathways and gene set enrichment}

Differentially expressed genes between the subgroups were defined, and gene set enrichment analysis was performed to identify the underlying pathways in each group using BioJupies tools. The DEGs were explored for common pathways using Metascape online tool (http://metascape.org) [10].

\section{Estimating immune and stromal cells in the synovium}

In order to achieve this goal, we used a recently available tool called ESTIMATE (Estimation of STromal and Immune cells in MAlignant Tumor tissues using Expression data) to estimate the difference in the infiltration of immune cells in healthy, OA and RA synovium. ESTI MATE $R$ package was used to estimate the difference in immune cells' infiltration between the three groups using their transcriptomic profile.

\section{Estimating infiltrating immune cells and their activation status in the synovium}

The raw RNAseq data were used for in silico prediction of the immune cells' infiltration of the synovial tissue using CIBERSORT analytical tool to evaluate the pre versus post tDMARDs changes in the immune population and/or activation status. Then, patients were divided according to the level of alteration in immune cells percentage after the treatment. The immune cells that express a higher level of the identified receptor were explored using the Database of Immune Cell Expression (DICE) project tool (https://dice-database.org/). The expression of the chemokine receptor was searched in a microarray dataset (GSE77298) of synovial biopsies of RA and healthy controls.

\section{Results}

RA synovium express genes related to immune cells activation, migration, signaling, and response to viruses For a better understanding of the RA disease pathogenesis, we reanalyze the gene expression profile of synovial tissue from $33 \mathrm{RA}$ and compare to samples from $26 \mathrm{OA}$ and 20 healthy controls. Our results showed that RA synovium expresses a specific signature that can differentiate it clearly from $\mathrm{OA}$ as well as healthy controls. This includes cytokine-mediated signaling pathway, positive regulation of cytokine production, Interleukin-2 family signaling, $\mathrm{T}$ cell receptor signaling pathway, leukocyte migration, negative regulation of chemotaxis, cellular response to interleukin-1, $\mathrm{T}$ cell activation, and 


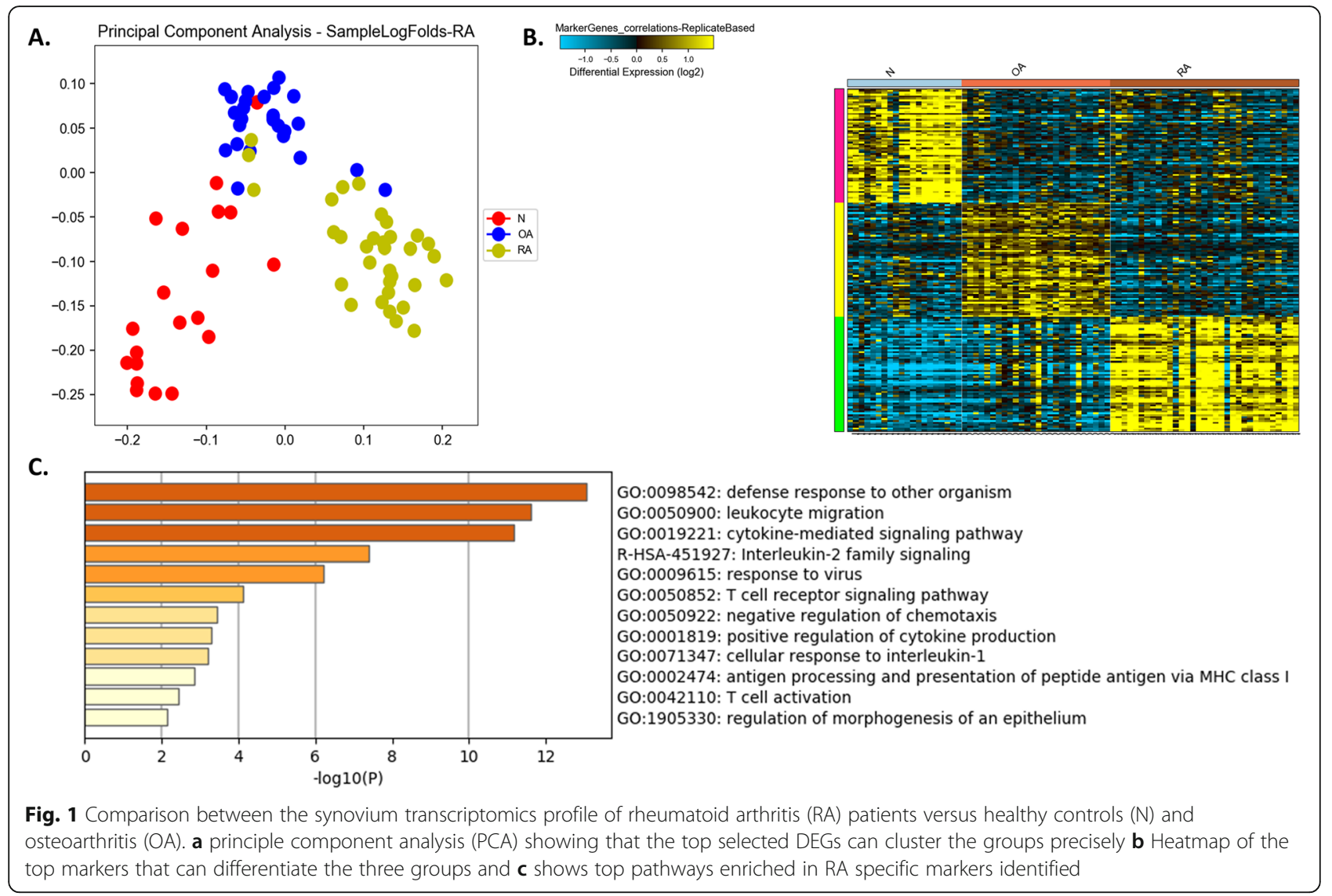

regulation of morphogenesis of an epithelium. Moreover, pathways related to defense response to other organisms, antigen processing and presentation of peptide antigen via major histocompatibility complex (MHC) class I and response to the virus were also enriched specifically in RA synovium. (Fig. 1, Tables 1 and 2).

\section{RA synovium express higher CCL5 and its receptor CCR5} Next and in order to investigate the role of the main cytokines that control the immune response including cell number, activation, maturation, differentiation, and migration, we filtered the top DEGs between the three groups (healthy, OA, and RA) to look for chemokines and interleukins only. Interestingly, RA synovium showed significantly higher expression of important chemokines ligands (CCL18, CXCL9, CXCL10, CXCL13 CCL5, and its receptor CCR5). Moreover, RA synovium expresses higher interleukins related genes (IL21R, IL32, IL2RG) (Table 3).

RA synovium showed a higher infiltration of plasma cells, CD4 memory $T$ cells, and gamma delta $T$ cells but less dendritic and activated NK cells

In order to decipher the effect of infiltrating immune cells to the synovium and their status of activation, which might mask the local gene expression and can explain the dynamics of immune cells in disease pathophysiology, we explored the immune infiltration using in silico tools. RA synovium showed a significantly higher level of infiltrating immune cells compared to OA and healthy controls confirming the DEGs and pathways enrichment results. Specifically, RA synovium showed higher infiltration of plasma cells, CD4 memory $\mathrm{T}$ cells, and gamma delta $\mathrm{T}$ cells but less dendritic and activated NK cells (Fig. 2).

SARS-COV-2 infected lungs express more CCL4, CCL8, and CCL11 that share CCR5 as a common receptor

Next, we tried to understand some of the molecular mechanisms involved in SARS-COV-2 pathogenesis with potential interaction with the mechanisms and pathways involved in RA. Eighty-four DEGs were identified between uninfected and COVID-19 infected lung samples. These DEGs were enriched in pathways specific to (response to the virus, response to interferon, leukocyte activation, and chemotaxis) Interestingly, SARS-COV-2 infected lungs express more CCL4, CCL8, and CCL11; the three ligands shared the same receptor, which is CCR5 (Fig. 3). Top immune cells that express CCR5 
Table 1 Top Genes that are specific to healthy, OA, and RA synovium

\begin{tabular}{|c|c|c|c|c|c|c|}
\hline \multirow[t]{2}{*}{ ID } & \multicolumn{2}{|c|}{ Markers Specific to Healthy } & \multicolumn{2}{|c|}{ Markers Specific to OA } & \multicolumn{2}{|c|}{ Markers Specific to RA } \\
\hline & Probeset_id & Gene Name & Probeset_id & Gene Name & Probeset_id & Gene Name \\
\hline 1 & 204180_s_at & ZBTB43 & 204284_at & PPP1R3C & 210538_s_at & BIRC3 \\
\hline 2 & 204131_s_at & $\mathrm{FOXO3}$ & 217963_s_at & NGFRAP1 & 217933_s_at & LAP3 \\
\hline 3 & 213649_at & SFRS7 & 219197_s_at & SCUBE2 & 204279_at & PSMB9 \\
\hline 4 & 222303_at & & 212256_at & GALNT10 & 216920_s_at & TARP \\
\hline 5 & 204243_at & RLF & 203478_at & NDUFC1 & 211798_x_at & IGLJ3 \\
\hline 6 & 222164_at & FGFR1 & 205330_at & MN1 & 217281_x_at & IGHV3-7 \\
\hline 7 & 206359_at & SOCS3 & 218126_at & FAM82A2 & 209924_at & CCL18 \\
\hline 8 & 201160_s_at & CSDA & 210534_s_at & B9D1 & 217179_x_at & \\
\hline 9 & 209682_at & CBLB & 202016_at & MEST & 214973_x_at & IGHD \\
\hline 10 & 215330_at & & 204776_at & THBS4 & 209267_s_at & SLC39A8 \\
\hline 11 & 219228_at & ZNF331 & 204797_s_at & EML1 & 218223_s_at & PLEKHO1 \\
\hline 12 & 204748_at & PTGS2 & 201842_s_at & EFEMP1 & 211644_x_at & IGKV3-20 \\
\hline 13 & 210764_s_at & CYR61 & 205364_at & ACOX2 & 205159_at & CSF2RB \\
\hline 14 & 218859_s_at & ESF1 & 214620_x_at & PAM & 212956_at & TBC1D9 \\
\hline 15 & 201465_s_at & JUN & 210997_at & HGF & 206247_at & MICB \\
\hline 16 & 220046_s_at & CCNL1 & 219953_s_at & C11orf17 & 217378_x_at & LOC100130100 \\
\hline 17 & 200921_s_at & BTG1 & 208792_s_at & CLU & 205488_at & GZMA \\
\hline 18 & 202768_at & FOSB & 210302_s_at & MAB21L2 & 211643_x_at & \\
\hline 19 & 209184_s_at & IRS2 & 219182_at & FLJ22167 & 205569_at & LAMP3 \\
\hline 20 & 213462_at & NPAS2 & 215913_s_at & GULP1 & 211637_x_at & IGHV4-4 \\
\hline 21 & 200702_s_at & $\mathrm{DD} \times 24$ & 37408_at & MRC2 & 205831_at & $\mathrm{CD} 2$ \\
\hline 22 & 218880_at & FOSL2 & 213167_s_at & SLC5A3 & 213716_s_at & SECTM1 \\
\hline 23 & 210094_s_at & PARD3 & 207326_at & BTC & 209670_at & TRAC \\
\hline 24 & 207316_at & HAS1 & 207447_s_at & MGAT4C & 206991_s_at & CCR5 \\
\hline 25 & 210180_s_at & SFRS10 & 222125_s_at & P4HTM & 214916_x_at & \\
\hline 26 & 208707_at & EIF5 & 206439_at & EPYC & 216401_x_at & LOC652493 \\
\hline 27 & 220266_s_at & KLF4 & 205127_at & PTGS1 & 214768_x_at & FAM20B \\
\hline 28 & 212501_at & CEBPB & 218837_s_at & UBE2D4 & 217480_x_at & LOC339562 \\
\hline 29 & 202340_x_at & NR4A1 & 209466_x_at & PTN & 204891_s_at & LCK \\
\hline 30 & 211458_s_at & GABARAPL1 & 205150_s_at & KIAA0644 & 211645_x_at & \\
\hline 31 & 201473_at & JUNB & 205898_at & CX3CR1 & 212314_at & KIAA0746 \\
\hline 32 & 212384_at & BAT1 & 212713_at & MFAP4 & 205267_at & POU2AF1 \\
\hline 33 & 200800_s_at & HSPA1A & 205817_at & SIX1 & 219648_at & MREG \\
\hline 34 & 202014_at & PPP1R15A & 201279_s_at & DAB2 & 210915_x_at & TRBC1 \\
\hline 35 & 204622_x_at & NR4A2 & 206070_s_at & EPHA3 & 216576_x_at & IGKC \\
\hline 36 & 210852_s_at & AASS & 205857_at & SLC18A2 & 217258_x_at & IGL@ \\
\hline 37 & 202861_at & PER1 & 205638_at & BAI3 & 213915_at & NKG7 \\
\hline 38 & 222162_s_at & ADAMTS1 & 206373_at & $\mathrm{ZIC1}$ & 204613_at & PLCG2 \\
\hline 39 & 215248_at & GRB10 & 220595_at & PDZRN4 & 221658_s_at & IL21R \\
\hline 40 & 214805_at & EIF4A1 & 218675_at & SLC22A17 & 202307_s_at & TAP1 \\
\hline 41 & 201810_s_at & SH3BP5 & 217511_at & KAZALD1 & 203528_at & SEMA4D \\
\hline 42 & 202948_at & IL1R1 & 206726_at & PGDS & 203828_s_at & IL32 \\
\hline 43 & 212732_at & MEG3 & 204933_s_at & TNFRSF11B & 201690_s_at & TPD52 \\
\hline
\end{tabular}


Table 1 Top Genes that are specific to healthy, OA, and RA synovium (Continued)

\begin{tabular}{|c|c|c|c|c|c|c|}
\hline \multirow[t]{2}{*}{ ID } & \multicolumn{2}{|c|}{ Markers Specific to Healthy } & \multicolumn{2}{|c|}{ Markers Specific to OA } & \multicolumn{2}{|c|}{ Markers Specific to RA } \\
\hline & Probeset_id & Gene Name & Probeset_id & Gene Name & Probeset_id & Gene Name \\
\hline 44 & 217911_s_at & BAG3 & 211958_at & IGFBP5 & 214777_at & IGKV4-1 \\
\hline 45 & 200768_s_at & MAT2A & 221447_s_at & GLT8D2 & 216207_x_at & IGKV1D-13 \\
\hline 46 & 221031_s_at & APOLD1 & 205833_s_at & PART1 & 206082_at & HCP5 \\
\hline 47 & 202672_s_at & ATF3 & 203440_at & $\mathrm{CDH} 2$ & 208885_at & LCP1 \\
\hline 48 & 212227_x_at & EIF1 & 204749_at & NAP1L3 & 1405_i_at & CCL5 \\
\hline 49 & 203752_s_at & JUND & 221029_s_at & WNT5B & M97935_3_at & STAT1 \\
\hline 50 & 202431_s_at & MYC & 207497_s_at & MS4A2 & 204116_at & IL2RG \\
\hline 51 & 213006_at & CEBPD & 210372_s_at & TPD52L1 & 209374_s_at & $\mathrm{IGHM}$ \\
\hline 52 & 201531_at & ZFP36 & 210006_at & ABHD14A & 209606_at & CYTIP \\
\hline 53 & 203140_at & $\mathrm{BCL6}$ & 220076_at & ANKH & 204533_at & CXCL10 \\
\hline 54 & 36711_at & MAFF & 213195_at & LOC201229 & 202270_at & GBP1 \\
\hline 55 & 208869_s_at & GABARAPL1 & 204773_at & IL11RA & 219386_s_at & SLAMF8 \\
\hline 56 & 209681_at & SLC19A2 & 219416_at & SCARA3 & 205890_s_at & GABBR1 \\
\hline 57 & 212665_at & TIPARP & 206089_at & NELL1 & 205242_at & CXCL13 \\
\hline 58 & 202284_s_at & CDKN1A & 219561_at & COPZ2 & 206134_at & ADAMDEC1 \\
\hline 59 & 209305_s_at & GADD45B & 206480_at & LTC4S & 203915_at & CXCL9 \\
\hline 60 & 203574_at & NFIL3 & 205475_at & SCRG1 & 206513_at & AIM2 \\
\hline
\end{tabular}

were $\mathrm{CD} 4 \mathrm{~T}$ memory $\mathrm{T}$ reg cells, Th17, Th1, and monocytes.

tDMARDs treatment in early RA increase synovial activated natural killers and resting mast cells but decrease plasma cells and M1 macrophages

Next, we tried to investigate the effect of tDMARDs on immune modulation, which might improve our understanding of its role in the treatment of RA as well as other diseases like COVID-19 infection. To achieve this, we investigated the effect of the treatment of tDMARDs on different immune cell populations of the synovium. Our results showed that four immune cell populations were significantly changed after six months of tDMARDs. This includes the resting mast cells and activated NK cells that were shown to be increased by 84 and $74 \%$ of patients, respectively. On the other hand, M1 macrophages and plasma cells were decreased after treatment in 68 and $58 \%$ of patients, respectively (Fig. 4).

DMARDs can block RA pathogenic CCR5 rich immune cell recruitment

Further analysis confirmed our previous finding that CCR5 was significantly upregulated in RA compared to healthy controls synovium $(p=0.04)$, Fig (5a). Moreover, our results also showed that this receptor was dramatically downregulated after six months of tDMARDs treatment $(p=0.004)$, as shown in Fig. (5b). Those results highlighted a possible beneficiary effect of DMARDs in patients with COVID-19, through its ability to block
CCR5 rich immune cell recruitment that we already found to be upregulated in the SARS-COV-2 infected lungs.

\section{Discussion}

Since the outbreak of COVID-19 infection, it was evident that this disease had a variable clinical impact on different subpopulations [2, 3]. Due to the immune dysregulation as well as the use of immune-modulating treatments, patients with rheumatic diseases were considered among the fragile subpopulations that might suffer from the more aggressive form of COVID-19 [4-6]. Interestingly, a group of disease-modifying antirheumatic drugs (DMARDS), including HCQ and IL6 inhibitors such as tocilizumab, was also proposed as a possible therapeutic option to treat COVID-19 patients [20]. However, the mechanisms through which those agents produce their effect is not fully understood.

Chloroquine and hydroxychloroquine showed antiviral characteristics in vitro, and some reports showed their efficacy in the treatment of COVID-19 [8]. It is suggested that these drugs interfere with lysosomal activity, membrane stability, signaling pathways, and immunerelated transcriptional activity [21].

Therefore, a better understanding of the relationship between RA and its associated therapies and COVID-19 disease might help to improve the response to COVID19 pandemic. Our results here highlight a possible link between RA and COVID-19, which might explain the 
Table 2 Top Pathways enriched in the DEGs specific to RA compared to healthy and OA

\begin{tabular}{|c|c|c|c|c|c|c|}
\hline Category & Term & Description & LogP & $\begin{array}{l}\text { Log(q- } \\
\text { value) }\end{array}$ & $\begin{array}{l}\text { InTerm_ } \\
\text { InList }\end{array}$ & Symbols \\
\hline $\begin{array}{l}\text { GO } \\
\text { Biological } \\
\text { Processes }\end{array}$ & $\begin{array}{l}\text { GO: } \\
0098542\end{array}$ & $\begin{array}{l}\text { defense response to other } \\
\text { organism }\end{array}$ & -13.0634 & -8.744 & $16 / 596$ & $\begin{array}{l}\text { BIRC3, GBP1, IGHD, IGHM, IGKC, CXCL10, MICB, CXCL9, STAT1, } \\
\text { AIM2, CXCL13, IGHV3-7, TRBC1, IGKV3-20, SLAMF8, IGLL5, CCR5, } \\
\text { CSF2RB, GZMA, PLCG2, CCL5, POU2AF1, IGKV4-1, LCK, PSMB9, } \\
\text { CD2, LCP1, TPD52, IL21R, TAP1, LAMP3, IGKV1D-13, IL2RG }\end{array}$ \\
\hline $\begin{array}{l}\text { GO } \\
\text { Biological } \\
\text { Processes }\end{array}$ & $\begin{array}{l}\text { GO: } \\
0050900\end{array}$ & leukocyte migration & -11.5986 & -7.757 & $14 / 504$ & $\begin{array}{l}\text { CD2, CCR5, IGHM, IGKC, CXCL10, LCK, CXCL9, CCL5, CCL18, } \\
\text { CXCL13, IGHV3-7, IGKV4-1, IGKV3-20, SLAMF8, CSF2RB, IL2RG, } \\
\text { IL21R, STAT1, PLCG2, SLC39A8, SEMA4D, PLEKHO1, FAM20B, } \\
\text { ADAMDEC1, GABBR1, AIM2, BIRC3, NCOR2, GBP1 }\end{array}$ \\
\hline $\begin{array}{l}\mathrm{GO} \\
\text { Biological } \\
\text { Processes }\end{array}$ & $\begin{array}{l}\text { GO: } \\
0019221\end{array}$ & $\begin{array}{l}\text { cytokine-mediated signaling } \\
\text { pathway }\end{array}$ & -11.1576 & -7.441 & 16/796 & $\begin{array}{l}\text { BIRC3, CCR5, CSF2RB, GBP1, IL2RG, CXCL10, LCP1, CXCL9, PSMB9, } \\
\text { CCL5, CCL18, STAT1, IL32, AIM2, CXCL13, IL21R, LCK }\end{array}$ \\
\hline $\begin{array}{l}\text { Reactome } \\
\text { Gene Sets }\end{array}$ & $\begin{array}{l}\text { R-HSA- } \\
451927\end{array}$ & Interleukin-2 family signaling & -7.38881 & -4.517 & $5 / 44$ & CSF2RB, IL2RG, LCK, STAT1, IL21R, CCR5, GZMA, TAP1 \\
\hline $\begin{array}{l}\text { GO } \\
\text { Biological } \\
\text { Processes }\end{array}$ & $\begin{array}{l}\text { GO: } \\
0009615\end{array}$ & response to virus & -6.22631 & -3.606 & $8 / 334$ & $\begin{array}{l}\text { BIRC3, GBP1, CXCL10, MICB, CXCL9, CCL5, STAT1, AIM2, PSMB9, } \\
\text { CCL18, PLCG2, SLAMF8, LCK, LAMP3, CCR5, TAP1 }\end{array}$ \\
\hline $\begin{array}{l}\text { GO } \\
\text { Biological } \\
\text { Processes }\end{array}$ & $\begin{array}{l}\text { GO: } \\
0050852\end{array}$ & $\begin{array}{l}\text { T cell receptor signaling } \\
\text { pathway }\end{array}$ & -4.11131 & - & $5 / 202$ & $\begin{array}{l}\text { GBP1, LCK, PLCG2, PSMB9, TRBC1, CD2, TPD52, SLAMF8, BIRC3, } \\
\text { STAT1, MICB }\end{array}$ \\
\hline $\begin{array}{l}\text { GO } \\
\text { Biological } \\
\text { Processes }\end{array}$ & $\begin{array}{l}\text { GO: } \\
0050922\end{array}$ & $\begin{array}{l}\text { negative regulation of } \\
\text { chemotaxis }\end{array}$ & -3.43346 & -1.270 & $3 / 64$ & $\begin{array}{l}\text { SEMA4D, CXCL13, SLAMF8, GBP1, LCK, CCL5, CYTIP, ADAMDEC1, } \\
\text { CCL18, AIM2, TBC1D9, SLC39A8, CXCL10, PLCG2, MICB }\end{array}$ \\
\hline $\begin{array}{l}\text { GO } \\
\text { Biological } \\
\text { Processes }\end{array}$ & $\begin{array}{l}\text { GO: } \\
0001819\end{array}$ & $\begin{array}{l}\text { positive regulation of cytokine } \\
\text { production }\end{array}$ & -3.28901 & -1.157 & $6 / 467$ & BIRC3, CD2, IGHD, PLCG2, STAT1, AIM2, GBP1, CCL5, LCP1 \\
\hline $\begin{array}{l}\text { GO } \\
\text { Biological } \\
\text { Processes }\end{array}$ & $\begin{array}{l}\text { GO: } \\
0071347\end{array}$ & $\begin{array}{l}\text { cellular response to } \\
\text { interleukin-1 }\end{array}$ & -3.19668 & -1.073 & $4 / 180$ & GBP1, PSMB9, CCL5, CCL18, STAT1 \\
\hline $\begin{array}{l}\mathrm{GO} \\
\text { Biological } \\
\text { Processes }\end{array}$ & $\begin{array}{l}\text { GO: } \\
0002474\end{array}$ & $\begin{array}{l}\text { antigen processing and } \\
\text { presentation of peptide } \\
\text { antigen via MHC class I }\end{array}$ & -2.85603 & -0.782 & $3 / 101$ & MICB, PSMB9, TAP1 \\
\hline $\begin{array}{l}\mathrm{GO} \\
\text { Biological } \\
\text { Processes }\end{array}$ & $\begin{array}{l}\text { GO: } \\
0042110\end{array}$ & $\mathrm{~T}$ cell activation & -2.4476 & -0.425 & $5 / 472$ & CD2, LCK, LCP1, MICB, CCL5 \\
\hline $\begin{array}{l}\mathrm{GO} \\
\text { Biological } \\
\text { Processes }\end{array}$ & $\begin{array}{l}\text { GO: } \\
1905330\end{array}$ & $\begin{array}{l}\text { regulation of morphogenesis } \\
\text { of an epithelium }\end{array}$ & -2.14316 & -0.163 & $3 / 181$ & CXCL10, PSMB9, STAT1, LCK, NCOR2 \\
\hline
\end{tabular}

Table 3 Top chemokine and interleukins related genes in the DEGs specific to RA compared to healthy and OA

\begin{tabular}{lllllllllll}
\hline Groups & Symbol & $\begin{array}{l}\text { log_fold-OA_- } \\
\text { vs_N }\end{array}$ & $\begin{array}{l}\text { adjp-OA_ } \\
\text { vs_N }\end{array}$ & $\begin{array}{l}\text { log_fold-RA_ } \\
\text { vs_N }\end{array}$ & $\begin{array}{l}\text { adjp-RA_ } \\
\text { vs_N }\end{array}$ & $\begin{array}{l}\text { log_fold-RA_vs_- } \\
\text { OA }\end{array}$ & $\begin{array}{l}\text { adjp-RA_vs_- } \\
\text { OA }\end{array}$ & $\begin{array}{l}\text { ANOVA- } \\
\text { rawp }\end{array}$ & $\begin{array}{l}\text { ANOVA- } \\
\text { adjp }\end{array}$ & $\begin{array}{l}\text { largest } \\
\text { fold }\end{array}$ \\
\hline Healthy & IL1R1 & -1.04318 & $3.14 \mathrm{E}-06$ & -1.08606 & $4.87 \mathrm{E}-08$ & -0.04288 & 0.835425 & $1.84 \mathrm{E}-12$ & $2.15 \mathrm{E}-10$ & 1.086057 \\
OA & CX3CR1 & 2.285902 & $9.5 \mathrm{E}-11$ & 1.231936 & $2.49 \mathrm{E}-05$ & -1.05397 & $1.18 \mathrm{E}-05$ & $3.35 \mathrm{E}-15$ & $1.12 \mathrm{E}-12$ & 2.285902 \\
OA & IL11RA & 0.938146 & $1.54 \mathrm{E}-05$ & -0.08216 & 0.711224 & -1.02031 & $4.32 \mathrm{E}-10$ & $1.52 \mathrm{E}-11$ & $1.25 \mathrm{E}-09$ & 1.020306 \\
RA & CCL5 & 0.164174 & 0.521514 & 1.630079 & $3.64 \mathrm{E}-09$ & 1.465904 & $1.42 \mathrm{E}-09$ & $1.17 \mathrm{E}-15$ & $4.92 \mathrm{E}-13$ & 1.630079 \\
RA & CCR5 & 0.34399 & 0.043302 & 1.251077 & $1.01 \mathrm{E}-10$ & 0.907087 & $9.01 \mathrm{E}-08$ & $2.75 \mathrm{E}-15$ & $9.57 \mathrm{E}-13$ & 1.251077 \\
RA & CCL18 & 0.355375 & 0.432754 & 2.165572 & $3.85 \mathrm{E}-09$ & 1.810197 & $6.47 \mathrm{E}-09$ & $1.86 \mathrm{E}-13$ & $3.26 \mathrm{E}-11$ & 2.165572 \\
RA & CXCL9 & 0.177374 & 0.57414 & 2.881994 & $7.72 \mathrm{E}-11$ & 2.704619 & $7.48 \mathrm{E}-13$ & $8.75 \mathrm{E}-21$ & $6.58 \mathrm{E}-17$ & 2.881994 \\
RA & CXCL10 & 0.462931 & 0.022287 & 2.326323 & $1.16 \mathrm{E}-10$ & 1.863391 & $5.94 \mathrm{E}-09$ & $1.66 \mathrm{E}-17$ & $1.91 \mathrm{E}-14$ & 2.326323 \\
RA & CXCL13 & 0.46977 & 0.094643 & 3.919964 & $4.83 \mathrm{E}-12$ & 3.450194 & $5.31 \mathrm{E}-11$ & $8.86 \mathrm{E}-21$ & $6.58 \mathrm{E}-17$ & 3.919964 \\
RA & IL2RG & 0.212245 & 0.311266 & 1.6011 & $7.46 \mathrm{E}-10$ & 1.388855 & $8.68 \mathrm{E}-10$ & $1.23 \mathrm{E}-16$ & $8.85 \mathrm{E}-14$ & 1.6011 \\
RA & IL32 & 0.40024 & 0.056249 & 1.659554 & $3.32 \mathrm{E}-10$ & 1.259314 & $4.85 \mathrm{E}-09$ & $4.25 \mathrm{E}-16$ & $2.37 \mathrm{E}-13$ & 1.659554 \\
RA & IL21R & 0.08408 & 0.495735 & 1.135477 & $1.03 \mathrm{E}-07$ & 1.051397 & $2.02 \mathrm{E}-08$ & $9.69 \mathrm{E}-15$ & $2.58 \mathrm{E}-12$ & 1.135477 \\
\hline
\end{tabular}




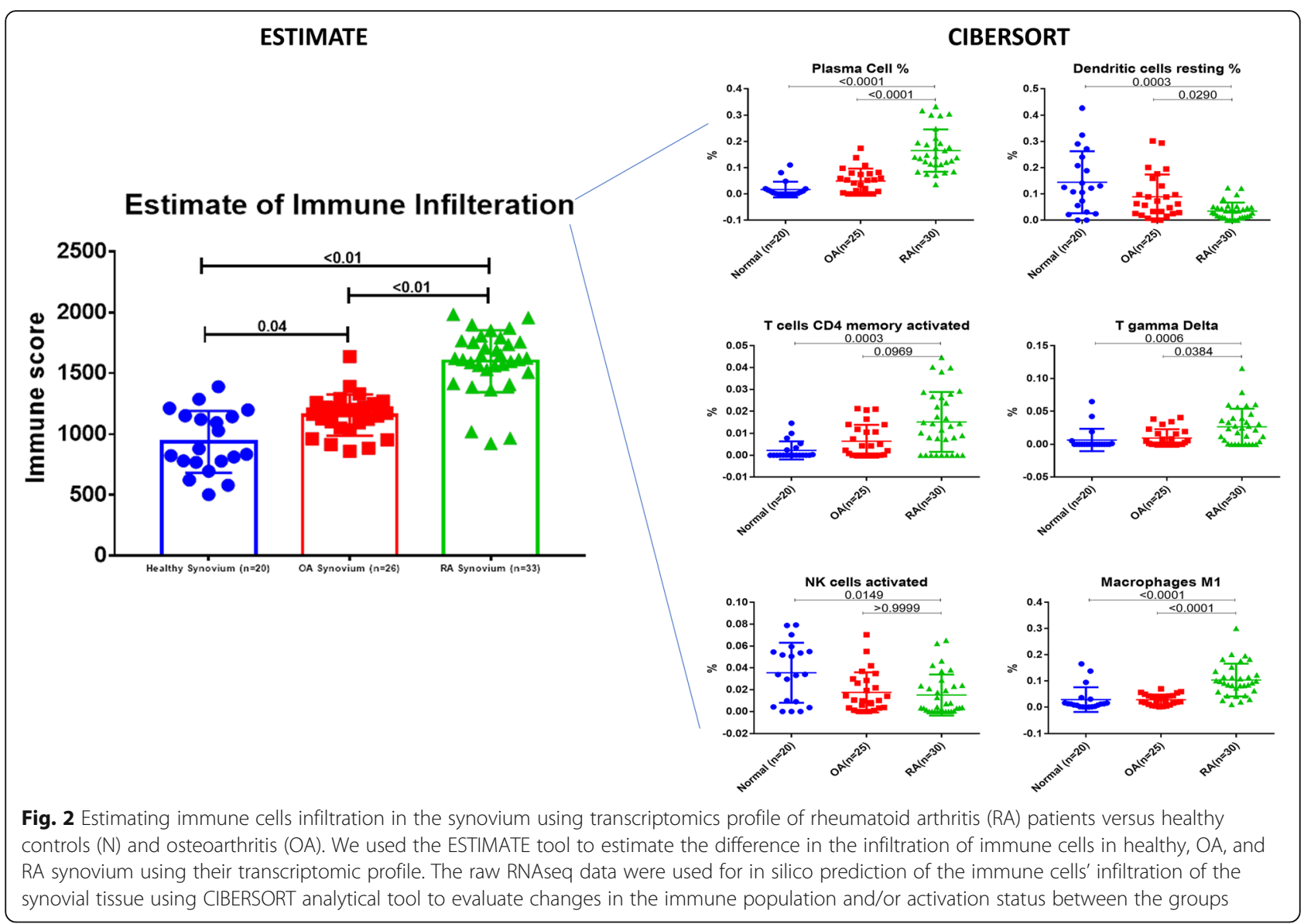

molecular basis of the benefits of some of the DMARDS used for treating COVID-19 infection.

Indeed, SARS-COV-2 infected lungs showed upregulation of chemotactic factors, including CCL4, CCL8, and CCL11, that all shared CCR5 as their receptor. This receptor is mainly expressed in the CD4 $\mathrm{T}$ memory, $\mathrm{T}$ reg cells, Th17, Th1, and monocytes.

Recent reports showed the importance of this receptor in the pathogenesis of RA. Indeed, CCR5 were found to be highly expressed in RA synovium, in addition to massive infiltration of the synovium with $\mathrm{T}$ helper cell type 1 inflammatory cell [22].

Our results showed that lungs infected with SARSCoV-2 express higher levels of CCL4, CCL8, and CCL11. CCL4 exhibit chemoattractive ability towards different cell types, including immune cells, and coronary endothelial cells [23]. CCL4 and its receptor CCR5 were reported to be significantly induced in the infarct myocardium, vulnerable atherosclerosis plaques, advanced atherosclerotic lesions, and to be associated with a higher risk of stroke and cardiovascular events [23]. The other chemokines ligand CCL8 is known to recruits further neutrophils to the infarct to release MMPs and soluble IL-6 [24]. CCL11 bind CCR3 to stimulates the migration of immune cells like neutrophils [25] and was shown to recruit such cells to the heart and contribute to myocardial fibrosis [26].

The pathogenesis of RA is suggested to involve Th1type $\mathrm{T}$ cells that preferentially express CCR5 where its chemokines ligands (macrophage inflammatory protein (Mip)-1 $\alpha$, CCL3; and Mip-1 $\beta$, CCL4) participate in selective recruitment of CCR 5 + CXCR3 + T cells to the inflamed synovium [27]. The infiltration of such IFN- $\gamma$ secreting CCR $5+\mathrm{CD} 4+\mathrm{T}$ cells into the RA joint cavity is regulated by the synovial microenvironment [28]. On the other hand, CCR5 silencing suppresses inflammatory response in RA by inhibiting synovial cell viability but promoting apoptosis [29]. Another source of CCR5 in RA are V $82 \mathrm{~T}$ cells which infiltrated into the synovium under the influence of high levels of TNF- $\alpha$ [30]. Moreover, an in vivo model using a non-functional form of the CCR5 receptor (CCR5- $\Delta 32)$ was shown to protect against RA [31, 32]. Carriers of the CCR5- $\Delta 32$ allele were at a significantly higher frequency in non-severe compared to severe patients making it a genetic marker related to the severity of RA [33]. 


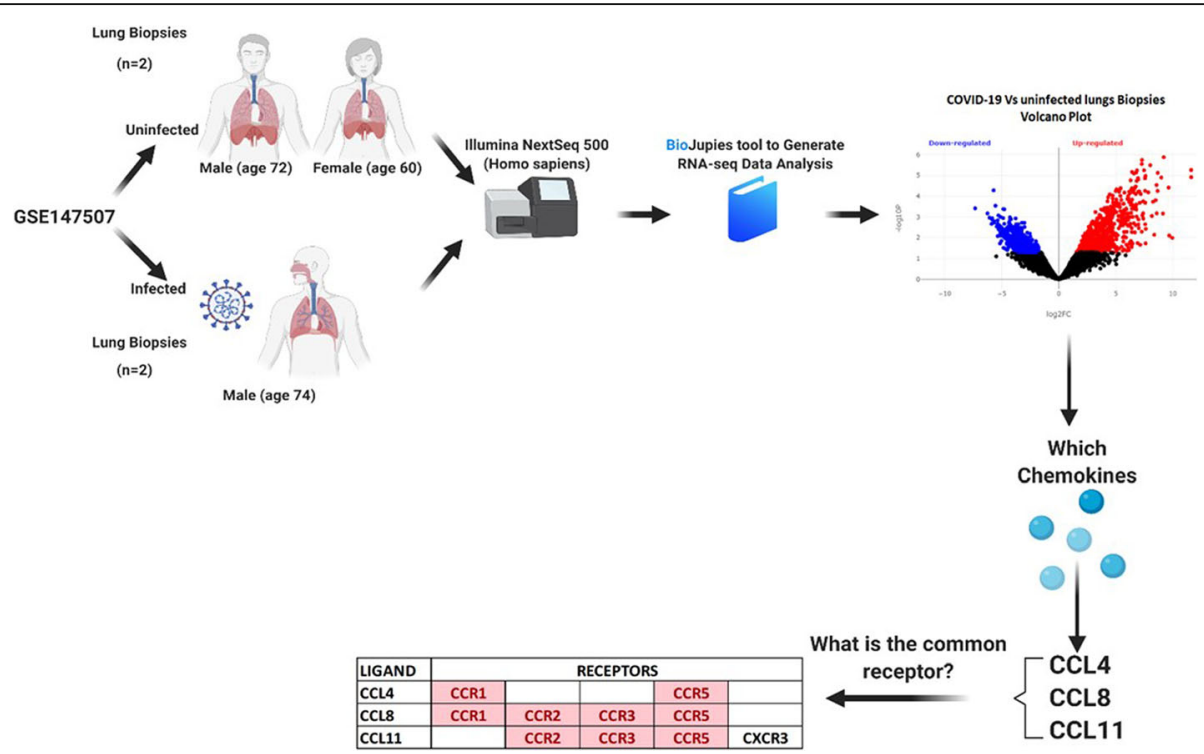

Fig. 3 Flowchart for identification of DEGs between SARS-CoV-2 infected and uninfected lung samples using RNAseq dataset (GSE147507) retrieved from GEO using BioJupies tools. The flow of transcriptomics reanalysis, identification of chemokines, their common receptors, and immune cells with high receptor are summarized

In COVID-19 patients, disruption of the CCL5-CCR5 axis through CCR5 blocking antibody leronlimab was shown to reduce plasma IL-6, and SARS-CoV-2 plasma viremia [34]. For that reason, leronlimab is currently under investigation in a Phase $2 \mathrm{~b} / 3$ for severely ill COVID-19 patients [35]. Interestingly, the CCR 532 allele was found to be an important genetic marker of SARS-CoV-2 related death [36].

The similarity that we observe here in the pathogenesis of both diseases might provide evidence about the molecular pathways through which many of the commonly used drugs for RA treatment are proposed to have benefits in COVID-19 management [4].

Another observation we notice here is the finding that the tDMARDs used for RA treatment was able to significantly upregulate some immune cell populations, including resting mast cells and activated NK cells. The recent observation that during the COVID19 infection, the main lymphocyte populations, including NK cells, were remarkably decreased, and this decrease was more prominent in the severe cases of COVID-19 infection compared to mild cases as well as healthy controls $[37,38]$. Moreover, another report also revealed that NK cells, in addition to the CD8+, were found to be important in modulating the antiCOVID-19 response [39].

This might explain the recent findings that patients with chronic arthritis treated with different forms of DMARD showed no evidence of increased risk of life-threatening or respiratory complications following the COVID-19 infection compared to the general population [4].
On the other hand, our reanalysis showed that tDMARDs significantly decrease the M1 macrophages and plasma cells, as shown in Fig. 4. It is known that the number and the level of activation of inflamed synovial macrophages correlate significantly with the severity of RA [40]. In RA, synovium can forms a niche for potentially autoreactive-B cells and plasma cells that play a central role in RA pathogensis [41]. The ability of tDMARDs to block these cells can explain its anti-RA effects.

Lung macrophages in severe COVID-19 infection orchestrate local inflammation by recruiting inflammatory monocytic cells and neutrophils, whereas, in moderate COVID-19 infection, macrophages produce more $\mathrm{T}$ cellattracting chemokines [42]. SARS-CoV-2 infection of alveolar macrophage can drive the "cytokine storm" that further damages multiple organs other than the lung, as in the case of heart and kidney [43].

During SARS-CoV-2 infections, immune cell subsets change, and among the $\mathrm{B}$ cells, the plasma cells increased remarkably, whereas the naïve B cells decreased [44]. Interestingly, one of the characteristics of the formation of SARS-CoV-2 anti-virus antibodies in a trial to limit viral replication is that these protective antibodies will cause friendly damage by the binding of the virus$\mathrm{Ab}$ complex to FcR on monocytes/macrophages induces pro-inflammatory responses that end up with the accumulation of pro-inflammatory M1 macrophages in the lungs escalating lung injury [45].

The ability of tDMARDs to significantly decrease the M1 macrophages and plasma cells can suggest that such drugs can be beneficial only in those who develop severe 

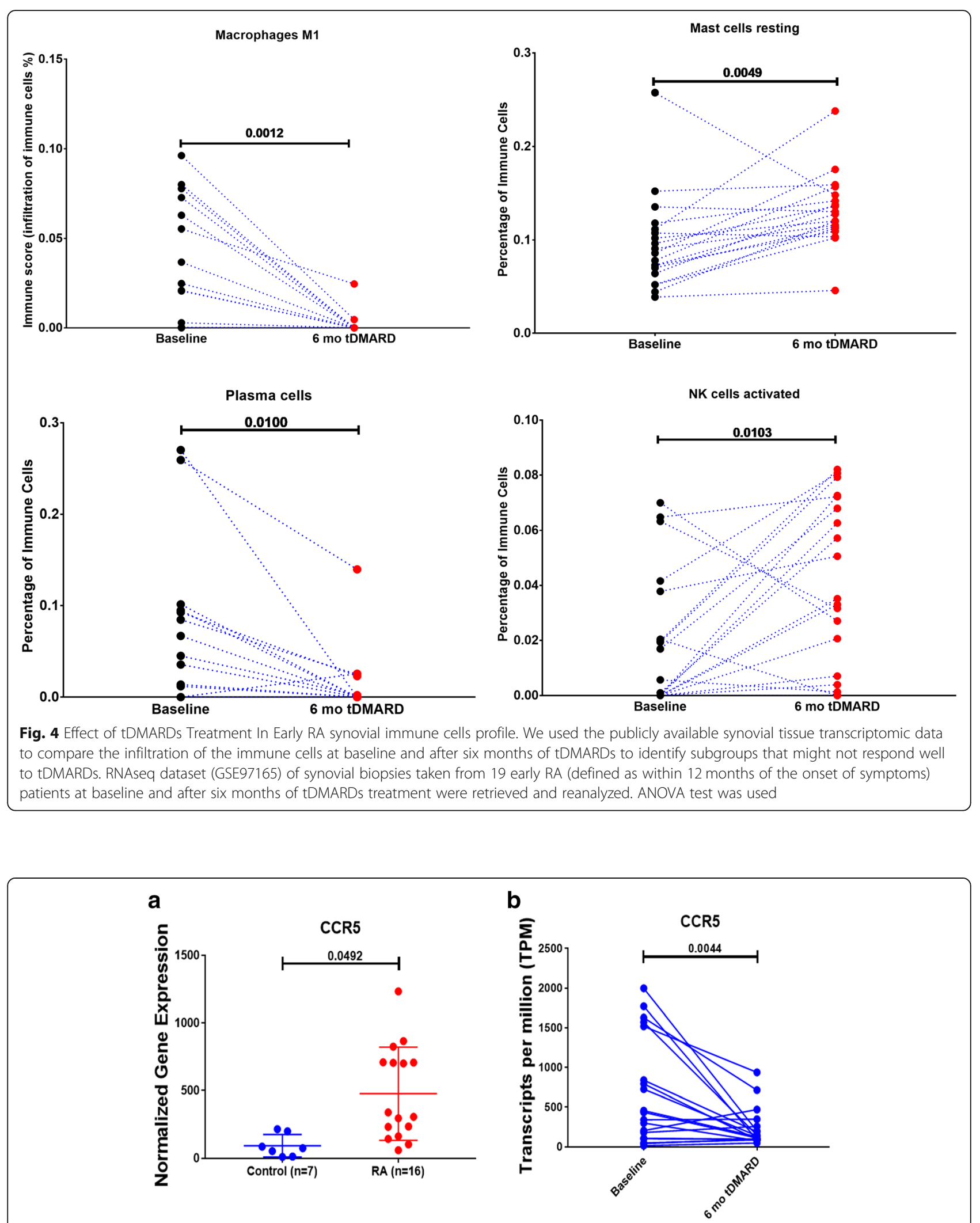

Fig. 5 CCR5 expression in synovial biopsies of RA and control and CCR5 expression at baseline and after six months of tDMARDs treatment. The expression of the chemokine receptor was searched in a microarray dataset (GSE77298) of synovial biopsies of RA and healthy controls. A paired T-test was used for comparison 


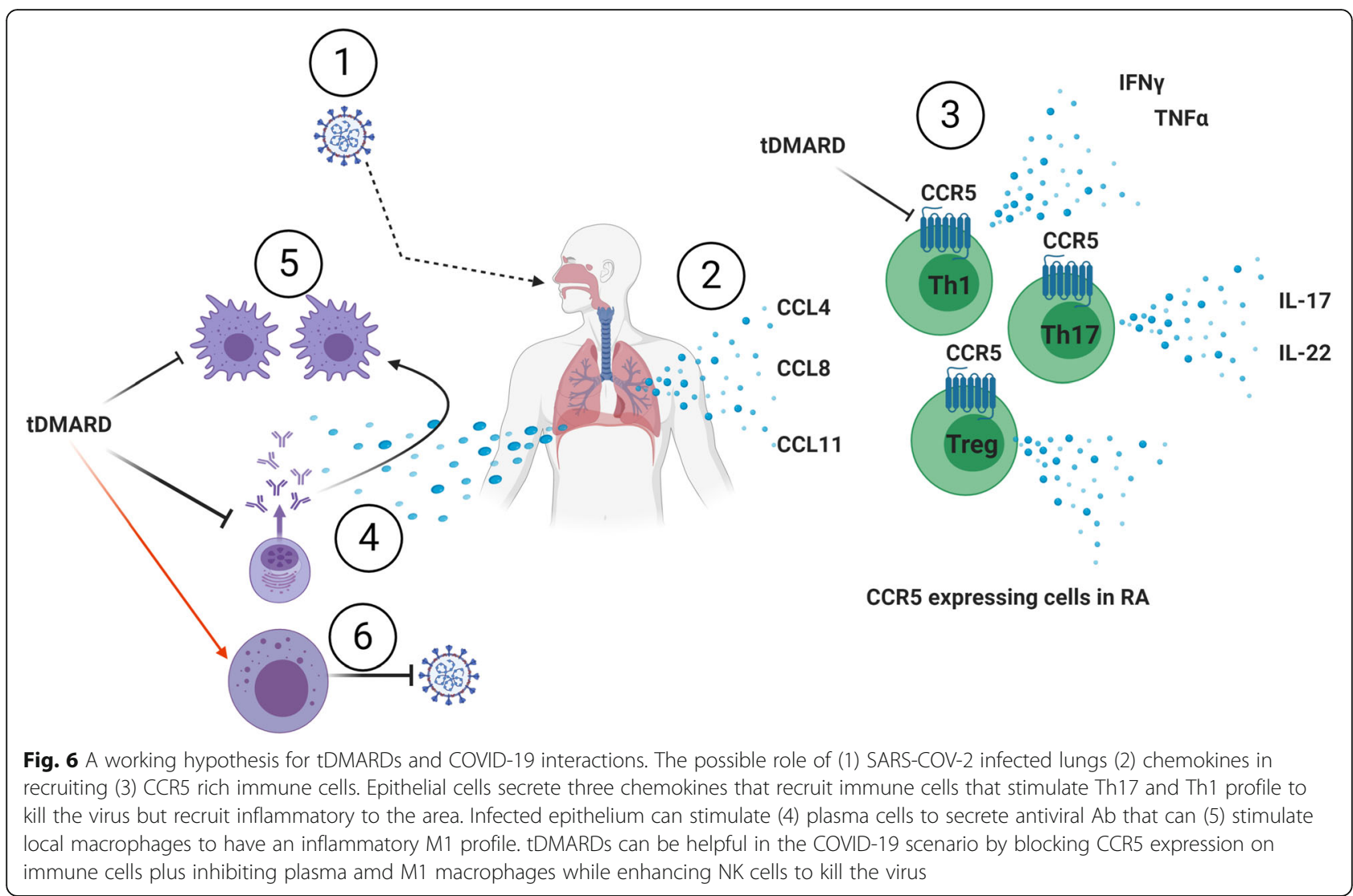

to moderate disease and have secondary antiviral antibodies, and this can explain why not all patients receiving such therapy are benefited from them.

In contrast, our results demonstrate a possible mechanism through which HCQ as a member of DMARDs might help in the management of COVID-19 infection, Fig (6). The possible role SARS-COV-2 infected lungs chemokines in recruiting CCR5 rich immune cells. Epithelial cells secrete three chemokines that recruit immune cells that stimulate Th17 and Th1 profile to kill the virus but recruit inflammatory to the area. Infected epithelium can stimulate plasma cells to secrete antiviral $\mathrm{Ab}$ that stimulates local macrophages to have an inflammatory M1 profile. tDMARDs can be helpful in the COVID-19 scenario by blocking CCR 5 expression on immune cells plus inhibiting plasma and M1 macrophages while enhancing NK cells to kill the virus.

Some issues to be considered carefully based on our results is that tDMARDs effect on CCR5 can inhibit Regulatory $\mathrm{T}$ (Treg) recruitment, which is required to inhibit the immune response and were reported to be reduced in severe COVID-19 patients [46]. Such an effect of HCQ might hamper innate and adaptive antiviral immune responses leading to growing uncertainty about these agents for the treatment of COVID-19 [47].

\section{Conclusion}

In summary, our results highlight common pathways that are involved in the pathogenesis of RA as well as COVID19. Those pathways might represent ideal targets for the discovery of more efficient and targeted therapeutic options to treat RA and COVID-19. Besides, it might help to improve our understanding of the mechanisms through which some of the medications are already used to treat COVID-19 infection, including the HCQ.

\section{Abbreviations \\ C-C : chemokine; COVID-19: coronavirus disease - 19; RA: rheumatoid arthritis; SARS-COV-2: severe acute respiratory syndrome-corona virus-2; tDMARDs: triple-DMARDs therapy; methotrexate, sulphasalazine, and $\mathrm{HCQ}$; NK: natural killer cells; DMARDs: Disease-Modifying Anti-Rheumatic Drugs; HCQ: Hydroxychloroquine; IL: interleukin; GEO: Gene Expression Omnibus; OA: osteoarthritis; DEGs: Differentially Expressed Genes; ESTIMATE: Estimation of STromal and Immune cells in MAlignant Tumor tissues using Expression data; DICE: Database of Immune Cell Expression; MHC: major histocompatibility complex}

\section{Acknowledgments}

We would like to thank all our patients for their patience. Also, we highly appreciate our colleagues and staff for their tremendous hard work during this crisis. In addition, we extend our gratitude to all staff at the Research Ethics Committee and the Information Technology Department for their help.

\section{Authors' contributions}

All authors have contributed equally. The authors read and approved the final manuscript. 


\section{Funding}

No funding.

\section{Availability of data and materials}

Data generated in the study are included in the tables.

\section{Ethics approval and consent to participate}

The study was approved by the Scientific Research Committee MOHAP/DXBREC/MMM/NO.44/2020 and certify that the study was performed in accordance with the ethical standards as laid down in the 1964 Declaration of Helsinki and its later amendments ethical standards.

\section{Consent for publication}

All authors have agreed to the publication and to be accountable for all aspects of the work in ensuring that questions related to the accuracy or integrity of any part of the work are appropriately investigated and resolved.

\section{Competing interests}

All authors declare no conflict of interest related to the current manuscript.

\section{Author details}

${ }^{1}$ College of Medicine, Mohammed bin Rashid University of Medicine and Health Sciences, Dubai, United Arab Emirates. ${ }^{2}$ Clinical Sciences Department, College of Medicine, University of Sharjah, Sharjah, UAE. ${ }^{3}$ Ministry of Health and Prevention (MOHAP), Dubai, UAE. ${ }^{4}$ The Royal Hospital, Muscat, Oman.

\section{Received: 23 July 2020 Accepted: 25 August 2020}

\section{Published online: 09 September 2020}

\section{References}

1. Lai C-C, et al. Severe acute respiratory syndrome coronavirus 2 (SARS-CoV-2) and coronavirus disease-2019 (COVID-19): the epidemic and the challenges. Int J Antimicrob Agents. 2020;55(3):105924.

2. Guan WJ, et al. Clinical characteristics of coronavirus disease 2019 in China. N Engl J Med. 2020;382(18):1708-20.

3. Wu Z, McGoogan JM. Characteristics of and important lessons from the coronavirus disease 2019 (COVID-19) outbreak in China: summary of a report of 72314 cases from the Chinese Center for Disease Control and Prevention. JAMA. 2020. https://doi.org/10.1001/jama.2020.2648. [Published online ahead of print, 2020 Feb 24].

4. Favalli EG, et al. COVID-19 infection and rheumatoid arthritis: Faraway, so close! Autoimmun Rev. 2020;19(5):102523.

5. Hsu CY, et al. Comparing the burdens of opportunistic infections among patients with systemic rheumatic diseases: a nationally representative cohort study. Arthritis Res Ther. 2019;21(1):211

6. Mehta B, et al. Serious infection risk in rheumatoid arthritis compared with non-inflammatory rheumatic and musculoskeletal diseases: a US national cohort study. RMD Open. 2019:5(1):e000935.

7. Kim AHJ, Sparks JA, Liew JW, et al. A rush to judgment? Rapid reporting and dissemination of results and its consequences regarding the use of hydroxychloroquine for COVID-19. Ann Intern Med. 2020;172(12):819-21. https://doi.org/10.7326/M20-1223.

8. Meo SA, Klonoff DC, Akram J. Efficacy of chloroquine and hydroxychloroquine in the treatment of COVID-19. Eur Rev Med Pharmacol Sci. 2020:24(8):4539-47.

9. Million M, Lagier JC, Gautret P, et al. Early treatment of COVID-19 patients with hydroxychloroquine and azithromycin: a retrospective analysis of 1061 cases in Marseille, France. Travel Med Infect Dis. 2020;35:101738. https://doi. org/10.1016/j.tmaid.2020.101738.

10. Luo $P$, et al. Tocilizumab treatment in COVID-19: a single center experience. J Med Virol. 2020;92(7):814-8.

11. Dale J, et al. Combination therapy for rheumatoid arthritis: methotrexate and sulfasalazine together or with other DMARDs. Nat Clin Pract Rheumatol. 2007:3(8):450-8 quiz, following 478.

12. Loffler BM, et al. Effects of antimalarial drugs on phospholipase a and lysophospholipase activities in plasma membrane, mitochondrial, microsomal and cytosolic subcellular fractions of rat liver. Biochim Biophys Acta. 1985:835(3):448-55.

13. Sperber $K$, et al. Selective regulation of cytokine secretion by hydroxychloroquine: inhibition of interleukin 1 alpha (IL-1-alpha) and IL-6 in human monocytes and T cells. J Rheumatol. 1993;20(5):803-8.
14. Ben-Zvi l, et al. Hydroxychloroquine: from malaria to autoimmunity. Clin Rev Allergy Immunol. 2012;42(2):145-53

15. Zhao M. Cytokine storm and immunomodulatory therapy in COVID-19: role of chloroquine and anti-IL-6 monoclonal antibodies. Int J Antimicrob Agents. 2020;55(6):105982.

16. Sinha N, Balayla G. Hydroxychloroquine and covid-19. Postgrad Med J. 2020 https://doi.org/10.1136/postgradmedj-2020-137785.

17. Hachim, M., et al., Estimating the infiltration of immune cells in Synovium of rheumatoid arthritis compared to osteoarthritis and healthy control using Transcriptomic profiling. 2019.

18. Hachim MY, et al. Identifying Asthma genetic signature patterns by mining Gene Expression BIG Datasets using Image Filtering Algorithms. In: 2019 IEEE International Conference on Imaging Systems and Techniques (IST); 2019.

19. Torre D, Lachmann A, Ma'ayan A. BioJupies: Automated Generation of Interactive Notebooks for RNA-Seq Data Analysis in the Cloud. Cell Systems. 2018;7(5):556-61 e3.

20. Zhong J, et al. The immunology of COVID-19: is immune modulation an option for treatment. Lancet Rheumatol. 2020;2(7):e428-36.

21. Schrezenmeier $E$, Dörner T. Mechanisms of action of hydroxychloroquine and chloroquine: implications for rheumatology. Nat Rev Rheumatol. 2020; 16(3):155-66.

22. Mellado $M$, et al. T cell migration in rheumatoid arthritis. Front Immunol. 2015:6:384.

23. Chang T-T, Chen J-W. Emerging role of chemokine CC motif ligand 4 related mechanisms in diabetes mellitus and cardiovascular disease: friends or foes? Cardiovasc Diabetol. 2016;15(1):117.

24. Jones DP, True HD, Patel J. Leukocyte trafficking in cardiovascular disease: insights from experimental models. Mediat Inflamm. 2017;2017:9746169.

25. Kindstedt $E$, et al. CCL11, a novel mediator of inflammatory bone resorption. Sci Rep. 2017;7(1):5334

26. Zweifel M, et al. Eotaxin/CCL11 levels correlate with myocardial fibrosis and mast cell density in native and transplanted rat hearts. Transplant Proc. 2010;42(7):2763-6

27. Patel DD, Zachariah JP, Whichard LP. CXCR3 and CCR5 ligands in rheumatoid arthritis Synovium. Clin Immunol. 2001;98(1):39-45.

28. WANG CR, LIU MF. Regulation of CCR5 expression and MIP-1a production in CD4+ T cells from patients with rheumatoid arthritis. Clin Exp Immunol. 2003:132(2):371-8

29. Lan Y-Y, Wang Y-Q, Liu Y. CCR5 silencing reduces inflammatory response, inhibits viability, and promotes apoptosis of synovial cells in rat models of rheumatoid arthritis through the MAPK signaling pathway. J Cell Physiol. 2019:234(10):18748-62.

30. Mo W-X, et al. Chemotaxis of V $\delta 2 T$ cells to the joints contributes to the pathogenesis of rheumatoid arthritis. Ann Rheum Dis. 2017;76(12):2075-84.

31. Zhou $Y$, et al. Impaired macrophage function and enhanced T celldependent immune response in mice lacking CCR5, the mouse homologue of the major HIV-1 coreceptor. J Immunol. 1998;160(8):4018-25.

32. Takeuchi T, Kameda H. What is the future of CCR5 antagonists in rheumatoid arthritis? Arthritis Res Ther. 2012;14(2):114.

33. Zapico I, et al. CCR5 (chemokine receptor-5) DNA-polymorphism influences the severity of rheumatoid arthritis. Genes Immun. 2000;1(4):288-9.

34. Patterson BK, Seethamraju H, Dhody K, et al. Disruption of the CCL5/ RANTES-CCR5 pathway restores immune homeostasis and reduces plasma viral load in critical COVID-19. Preprint. medRxiv. 2020;2020.05.02.20084673. https://doi.org/10.1101/2020.05.02.20084673. Published 2020 May 5.

35. Kumar RN, Tanna SD, Shetty AA, Stosor V. COVID-19 in an HIV-positive kidney transplant recipient. Transpl Infect Dis. 2020:e13338. https://doi.org/ 10.1111/tid. 13338

36. Panda AK, Padhi A, Prusty BAK. CCR5 $\Delta 32$ minorallele is associated with susceptibility to SARS-CoV-2 infection and death: An epidemiological investigation. Clini Chim Acta. 2020;510:60-1.

37. Qin C, Zhou L, Hu Z, et al. Dysregulation of immune response in patients with Coronavirus 2019 (COVID-19) in Wuhan, China. Clin Infect Dis. 2020; 71(15):762-8. https://doi.org/10.1093/cid/ciaa248.

38. Zheng Z, Peng F, Xu B, et al. Risk factors of critical \& mortal COVID-19 cases: a systematic literature review and meta-analysis. J Infect. 2020;81(2):e16-e25. https://doi.org/10.1016/j.jinf.2020.04.021.

39. Zheng $M$, et al. Functional exhaustion of antiviral lymphocytes in COVID-19 patients. Cell Mol Immunol. 2020;17(5):533-5.

40. Kinne RW, et al. Macrophages in rheumatoid arthritis. Arthritis Res. 2000;2(3): 189-202. 
41. Doorenspleet ME, et al. Rheumatoid arthritis synovial tissue harbours dominant B-cell and plasma-cell clones associated with autoreactivity. Ann Rheum Dis. 2014;73(4):756-62.

42. Liao M, et al. Single-cell landscape of bronchoalveolar immune cells in patients with COVID-19. Nat Med. 2020;26(6):842-4.

43. Wang $C$, et al. Alveolar macrophage dysfunction and cytokine storm in the pathogenesis of two severe COVID-19 patients. EBioMedicine. 2020;57: 102833.

44. Wen W, et al. Immune cell profiling of COVID-19 patients in the recovery stage by single-cell sequencing. Cell Discov. 2020;6:31.

45. Jafarzadeh A, et al. Contribution of monocytes and macrophages to the local tissue inflammation and cytokine storm in COVID-19: lessons from SARS and MERS, and potential therapeutic interventions. Life Sci. 2020;257: 118102

46. Liu L, Xu L, Lin C. T cell response in patients with COVID-19. Blood Sci. 2020; 2(3):76-8. https://doi.org/10.1097/BS9.0000000000000050.

47. Meyerowitz EA, et al. Rethinking the role of hydroxychloroquine in the treatment of COVID-19. FASEB J. 2020;34(5):6027-37.

\section{Publisher's Note}

Springer Nature remains neutral with regard to jurisdictional claims in published maps and institutional affiliations.

- fast, convenient online submission

- thorough peer review by experienced researchers in your field

- rapid publication on acceptance

- support for research data, including large and complex data types

- gold Open Access which fosters wider collaboration and increased citations

- maximum visibility for your research: over $100 \mathrm{M}$ website views per year

At BMC, research is always in progress. 